\title{
EFFECTS OF UNIFORMITY AND CONTRAST ON LIGHT.
}

\author{
By Hermann Bohle, F.R.S.S.Af.
}

(Read August 17, 1910).

In the planning of houses, halls, schools, and factories a good deal of sinning takes place as regards the lighting. The architectural features of the buildings receive preference. The questions of comfort and of adequate light are given second place; and yet, for the welfare and comfort of the inhabitants, they are of vital importance. My remarks hold for day- and artificial light. Even in this country, with an almost eternal sunshine, one often finds rooms badly lighted even on the brightest days. Why? Too much daylight cannot be brought into a room. The human eye can adapt itself without harm to almost any daylight illumination, as long as glare is avoided, and pass from a room with an illumination of forty candle-metres to an outside one of forty thousand without effort.* There is therefore no reason for making the inside illumination small; it should certainly not be smaller than one-hundredth part of the outside one.

Glare must, however, be avoided. An exact definition of glare has never been given. Some people define it as the intrinsic brilliancy, $\dagger$ which, when it exceeds a certain value--a value which depends on the individual-causes dazzling and pain to the eye. This definition of glare is not sufficient. If we look at the filament of an incandescent electric lamp in the evening we experience a dazzling sensation, or glare, but if we do so during the day the glare does not occur, or is at least greatly diminished. But the light is there all the same. Again, if we place a light in front of a black wall and look at it the glare appears strongly, whereas if it is placed before a white screen the glare vanishes. We see that intrinsic brilliancy alone does not constitute glare, and that contrast

* A candle-metre denotes the illumination given by a standard candle on a perfectly white screen at a metre distance, assuming that all rays fall perpendicularly upon the screen.

† Intrinsic brilliancy is the ratio of the normal intensity, measured in candles to the surface of the source. As regards the latter we should take the apparent source. 
plays an important part. In looking at a light before a dark screen the eye endeavours to do two things at once-the pupil tries to open wide to take in the dark background and to close up for the intrinsic brilliancy of the source. This phenomenon of double intentions really constitutes glare. The human eye tolerates enormous differences of diffused light, which we get from the light before a white screen, but it objects to high intrinsic brilliancy when it is accompanied by great contrasts such as a dark background.

A few remarks on the physiological effects of radiation may not be out of place.

The illuminants of old were of low power and great wave-length, the light being very red. With the advent of the gas mantle, the metal filament electric lamp, and the arc lamp, the light has become whiter and of much shorter wave-length. The lights of old were mostly too poor to enable people to work with artificial light; and this not being done, people suffered less from weak eyes than the present generation. Now the average person has to work three to four hours daily with artificial illumination, and it is therefore of the greatest importance that the work can be carried out with the least injury to the eyes. Many people have complained to me that electric light gives them headaches after an hour's working. They put it chiefly down to the high percentage of ultra-violet rays contained in the electric light. And yet daylight contains an even higher percentage of these rays, but it does not affect these persons.*

Without the slightest doubt modern illuminants have caused harm to the eyesight of many people. This is entirely due to improper illuminating engineering, whereby the destructive rays were given full scope, either by diffusing the light too little and causing simultaneous great contrasts or by directing the light wrongly. Even a small light-an ordinary wax candle-causes glare if it is directed into the eye under great contrasts. The eye attempts to do two things simultaneously. When contrasts are avoided the eye can protect itself. Moderate excesses are shut off by contraction of the pupil, sudden abnormal quantities of light by closing of the eyelids. Light has two different effects on the eye-the one is caused by the quantity, the other by the type of radiation.

Radiation is power. The light which enters the eye is absorbed and converted into heat. If the rate of conversion becomes too great the heating becomes excessive and the eyes give pain. If the "overheating" continues the eyes become inflamed and tears run. Was the time of overheating comparatively short, a few hours will see full recovery; otherwise, with continued excess absorption, the damage done may last

* I wish to point out here that the sunlight has an effect of this nature on me. By wearing, however, ordinary glasses (for shortsightedness) headaches practically disappear. An explanation will be given later on. 
for weeks. Temporary blindness is also due to sudden excess light absorption.

Daylight, the best diffused of all, causes less injury by overheating than artificial light. In the latter the percentage of visible radiation is small, the ultra-red portion containing most. But the light obtained from modern illuminants is caused by temperature radiation-hence the amount of power which enters the eye from artificial lights is much greater than from an equivalent daylight illumination. The latter is based on luminescence or selective radiation, possesses therefore a higher percentage of visible radiation, and is less harmful. It is, of course, assumed that direct looking into the sun, or into reflected sunlight, is avoided.

The type of radiation is also of great importance. The effects caused begin with the blue radiation and continue up to the $\mathrm{X}$-rays, the greatest effect being given by the extreme of the ultra-violet. The ultra-violet radiation extends far beyond the visible range. The visible part consists of long waves which are harmless as long as their intensity is limited. In artificial- and day-light they are moderately represented, and cause therefore little harm. The invisible portion may be divided into two sections-waves with a moderate frequency and such with high frequencies. The latter need hardly be considered here. They occur in a Geisler tube, but as the discharges take place within a glass tube the high-frequency waves are completely absorbed. They are also set up in a low-temperature mercury vapour arc, where they are again absorbed by the glass. Quartz does, however, not do so, and such lamps should therefore be avoided. In the high-temperature mercury vapour quartz lamp the high frequency ultra-violet rays do not occur.

Of greater importance are the rays of medium frequency, since they are set up in most modern illuminants. They are largely damped by clear glass. Consequently no one should look into a naked electric arc with the bare eye, as these rays are highly destructive. Moreover, the injury caused in this way is almost incurable. It is not external, but internal, and the eye loses the ability to keep anything in focus for any length of time.

Seeing that the ultra-violet rays are damaging to the eyesight we should guard against them. This can be done by the employment of proper globes. A mixture of red and green glass, giving a yellowish shade, will completely absorb the ultra-violet rays. Moreover, we should diffuse the light as much as possible, because by employing reflected light the ultra-violet rays are absorbed. It does not materially reduce the light, since the damaging ultra-violet rays take no part in giving light. As regards electric incandescent lighting, only such shades should be used which diffuse the light properly and obscure the lamp bulb. An advance 
in this direction is shown in the prismatic glass shade, the so-called holophane shade, which diffuses the light well. It is, however, not deep enough to obscure the lamp bulb, so that the light should be out of the line of vision. It would even be an improvement to make the bulb itself of red-green glass.

When light is properly diffused the eye is not called upon to do two things simultaneously, i.e., adapt itself to dark shadows and great intrinsic brilliancy at the same time. In wireless telegraphy, electric furnace work, electric welding, where naked arcs are employed, the operators should be protected by suitable glasses in order to prevent overheating and injury due to ultra-violet rays of medium frequency.

In taking once a number of students over some steel works at Sheffield we were shown, amongst other things, electric welding apparatus. As the number of protecting glasses was limited I looked for a few seconds with my naked eye at the arc, formed between the pieces to be welded together. The result was such injury to the eyes that they have not even fully recovered to-day. This was more than six years ago. I also remember waking up the following night with a maddening pain in my eyes, which felt as if they were full of pins and needles. It lasted for about an hour. Had I even worn ordinary clear glasses the effect would not have been so bad. In wearing glasses care should be taken that ultra-violet rays cannot enter the eye above or below the glasses.

Most people in this country will have experienced excessive glare at the seaside on sunny days. The illumination exceeds at noon often a hundred thousand candle-metres. The sunlight is largely reflected by the white sand, so that the intrinsic brilliancy is abnormally high. Moreover, the darkish sea provides a dark background, and glare is the result. Similar effects are shown in the Arctics, resulting finally in snow blindness. The latter may be avoided by the wearing of red and green glasses, as was proved by Sir Ernest Shackelton on his dash to the South Pole. Through glasses of this nature one may even look directly into the sun for minutes without harm. Headaches caused at the back of the eye by excess solar radiation or by artificial lights may also be prevented by the wearing of red and green glasses.

My remarks will have made the following points clear :-

(1) The illumination should be as uniform as possible.

(2) Direct light should be avoided.

(3) Naked lights should not be employed without adequate protection.

As regards (1), it is not difficult to produce a uniform illumination either during the day or at night.

Daylight can hardly be made excessive if glare is avoided. Nature has provided the eye with everything for its protection as long as glare does not occur. There is, therefore, from this standpoint nothing to be 
said in favour of large rooms and small window space. Moreover, light has a stimulating effect on the system in general, and as regards germs of disease, light is one of the most powerful therapeutic agents we possess. Germs of disease live in the dark, and to live at all, darkness is essential to them, whereas light destroys them. Hence we should build our houses with large windows, without black coverings, and let the sun enter the house irrespective of the fading of carpets. Factories should be so constructed that the light can simply pour into the workrooms, with the avoidance of glare. For equal surface, skylights allow more light to enter than vertical windows. So-called shed roofs should, therefore, be glazed on the least sloping surface, whereas the reverse is invariably the case. For skin tuberculosis, the sun is one of the most powerful agents for cure. If the evil sits deeper, the application of X-rays, applied moderately, might produce beneficial results. At the same time, we must remember that X-rays are of very high frequency, and, if used excessively, might cause dissociation of the treated part.

This may be explained as follows:-

Take a substance of small atomic weight, such as Oxigon. It will respond or resonate with high frequencies, somewhere near the extreme end of the ultra-violet. If, on the other hand, we employ a heavier substance, the frequency must decrease before a response takes place. This applies, for instance, to heavy carbon compounds, which respond to the low frequencies of the long waves between the red and the yellow. Hence ultra-violet rays, i.e., rays of high frequencies, must be harmful to plant life. The frequency is so great that the heavy groups of carbon cannot respond, but individual atoms may, and dissociation results. X-rays are even of higher frequency, and excess application must result in a dissociation of the treated parts.

Sun-burning is also due to excess exposure, but the skin protects the parts underneath and the stimulating effect largely counterbalances the discomfiture. Sun-baths are, therefore, highly to be recommended if applied in moderation. The same thing applies to electric baths, which will be found invigorating if excess is avoided.

After having dealt with the physiological effects of radiation, I shall consider how health and comfort may be obtained with artificial light.

Uniformity is again of great importance for preserving the eyesight. Clusters of lamps in the midale of a room should be avoided if possible. The arrangement of lamps distributed over the ceiling is preferable. It is, however, also more expensive on account of additional wiring. The uniformity becomes perfect by the application of indirect light. By means of shades the whole light of a number of distributed lights is thrown against the white ceiling from which it is reflected. About half the light is absorbed in this way, which constitutes a waste and the reason why 
inverted lamps are not oftener employed. From a series of experiments I come, however, to the conclusion that the waste is more apparent than real. For the purpose of carrying out the tests I had six tantalum lamps fixed to a wooden frame in such a manner that they could easily be provided with all kinds of shades and also be inverted. The lamps, or rather the illumination, were then tested by means of an illumination photometer, (1) in a room with jet-black walls and ceiling, and afterwards in an office of slightly larger size with a white ceiling and light yellow walls. The results are shown in Fig. 1. We notice that the illumination increases as we pass from the dark to the light room, the difference being shown by the lengths of the ordinates lying between the curves (1) and (3). I expected a much greater increase, but as three sets of experiments yielded the same result a mistake seems improbable. The six lamps were then provided with holophane shades, whereby the illumination in the test plane (horizontal, 1 metre above floor) was further increased. Finally, the room was illuminated with 4-40-watt Osram lamps within long fancy shades, pointing upwards under an angle of $45^{\circ}, 335$ centimetres above the floor. The result was a uniform illumination of 13 candle-metres.

Tests were made in reading text-book print by means of the various illuminations.

In the dark room, an illumination of 35 to 40 candle-metres seemed essential for comfort. It was, however, necessary to keep the eye on the book, as roaming about caused glare. In the light room, where contrast was almost absent even with the lamps hanging downwards, 25 to 30 candle-metres seemed sufficient, and roaming about the room with the eyes did not cause glare as long as one did not look directly into the filament.

When the lamps were inverted, and a perfectly uniform illumination resulted, comfort was achieved even with such a low illumination as 13 candle-metres. Twenty candle-metres gave perfect results. Moreover, glare was entirely absent, as the bulbs were out of the line of vision. We see, therefore, that although by indirect lighting we waste light, the resulting uniformity requires less. Moreover, the eye may easily adapt itself to great differences in illumination if the latter be uniform. I have seen it frequently stated lately that the human eye objects to an artificial illumination of more than 80 to 100 candle-metres. I do not agree with this. The eye, according to my own experience, will stand an enormous illumination if the latter is thoroughly aiffused and contrasts are avoided. If we could get daylight diffusion, and prevent contrast, the eye would stand thousands of candle-metres without harm.

Let us try to form a reason for the reduction in light required with an increase in uniformity, or rather with the avoidance of contrasts.*

* Curve 3 in Fig. 1, which was taken in the light room, does not show such a very great increase in the uniformity of the light. Contrast had, however, almost disappeared. 


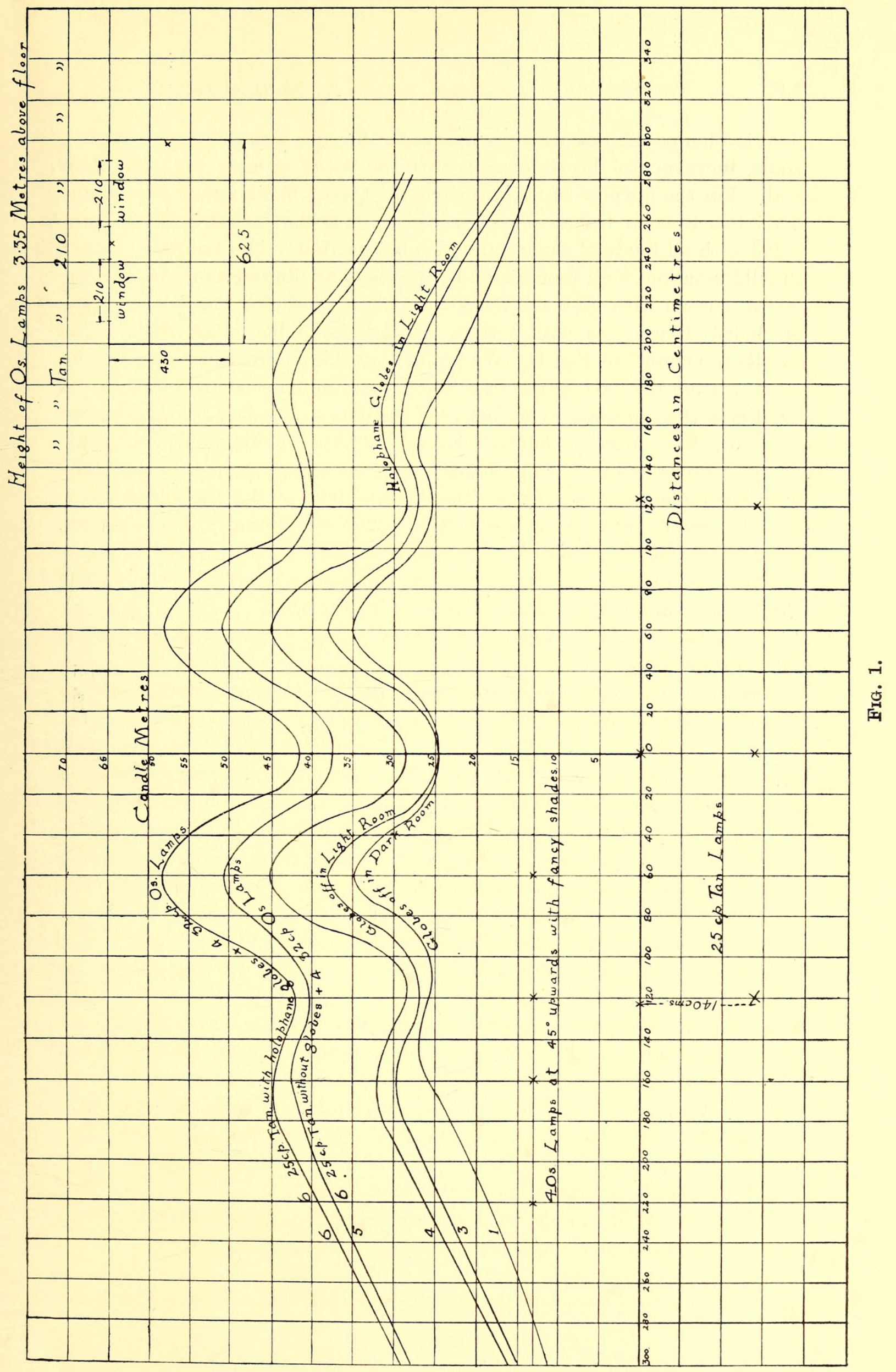




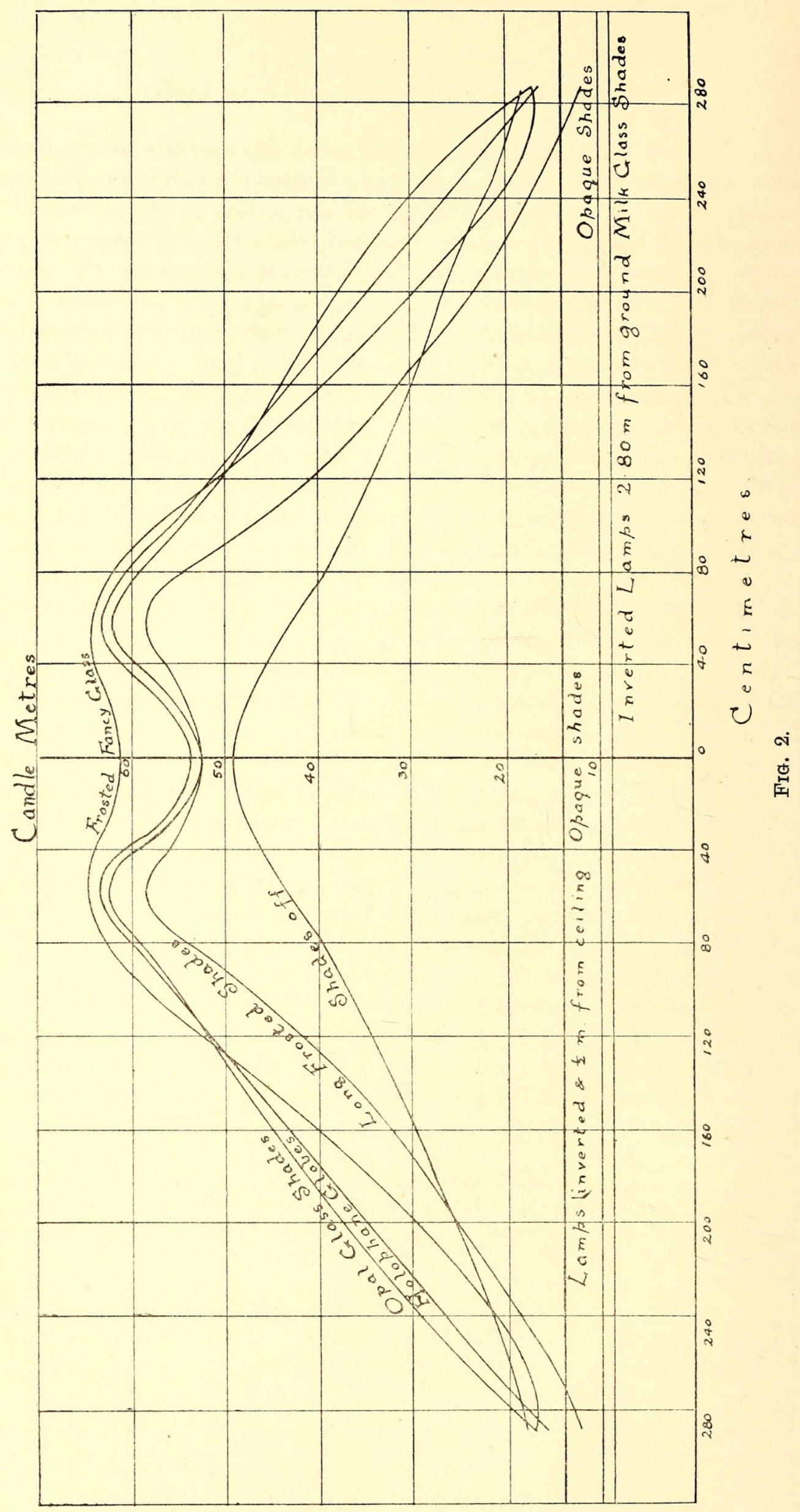


In the dark room, on looking at the print the aperture of the pupil becomes set to a certain width as long as one does not move the eye away from the book. At the same time one has the feeling of the surrounding blackness, and the great contrasts prevailing make the eye roam instinctively. As soon, however, as it encounters the blackness the pupil extends. In the next instant the eye strikes again the brilliantly illuminated paper, and consequently the pupil contracts, and apparently more than is necessary, because it experienced a glare. But too much contraction makes the illumination insufficient, and so the eye has to expand again. In other words, the aperture of the pupil alternately expands and contracts, making a higher average illumination necessary.

In a room with white walls and ceiling, and especially with uniform illumination, the eye does not experience any great contrasts, and it may consequently set itself definitely to a certain aperture, which does not alter even if the eye roams about the room. A smaller illumination is thus required, because the pupil can extend to a maximum without having to be afraid of glare.

It might be added here that even the ordinary black print on white paper causes some glare, and I have no doubt that for the preservation of the eyes coloured print would be preferable.

In conclusion, I add a few curves (Fig. 2) which deal with the illuminations derived from various types of lamp shades. The superiority as regards uniformity of the prismatic glass or holophane shade is strikingly illustrated. It might be further improved by lengthening the shade or surrounding it with a deep, slightly obscuring frosted globe. The long frosted shade, although it diffuses the light badly, hides the whole lamp bulb, and the filament is therefore invisible. The intrinsic brilliancy is thereby greatly reduced.*

All the tests were carried out on a horizontal plane 1 metre above the floor, as this is now recognised as the standard test plane. Testing the illumination of inclined planes would make it impossible to take into account the illumination from all sources taking part in the lighting of the regions to be tested.

* The holophane shades are somewhat expensive. Fig. 2 shows, however, that with the ordinary conical opal shade a uniformity superior to that of holophane globes may be obtained. The lamps must, however, be hung close to the ceiling, as the shades do not obscure the lamps. 


\section{$2 \mathrm{BHL}$ Biodiversity Heritage Library}

Bohle, Hermann. 1910. "EFFECTS OF UNIFORMITY AND CONTRAST ON

LIGHT." Transactions of the Royal Society of South Africa 2, 127-135.

https://doi.org/10.1080/00359191009519368.

View This Item Online: https://www.biodiversitylibrary.org/item/181596

DOI: https://doi.org/10.1080/00359191009519368

Permalink: https://www.biodiversitylibrary.org/partpdf/175481

\section{Holding Institution}

Smithsonian Libraries

\section{Sponsored by}

Biodiversity Heritage Library

\section{Copyright \& Reuse}

Copyright Status: Not in copyright. The BHL knows of no copyright restrictions on this item.

This document was created from content at the Biodiversity Heritage Library, the world's largest open access digital library for biodiversity literature and archives. Visit BHL at https://www.biodiversitylibrary.org. 